$1 \mathrm{P} 151$

\section{細胞質ダイニンの微小管上での運動は右方向にバイアスされ ている}

Cytoplasmic dynein takes a route switching randomly between protofilaments with a bias toward the right

Mitsuhiro Sugawa ${ }^{1}$, Shin Yamaguchi $^{1}$, Keitaro Shibata ${ }^{1,2}$, Yoko Y. Toyoshima ${ }^{1}$, Junichiro Yajima ${ }^{1}\left({ }^{1}\right.$ Grad. Sch. Arts \& Sciences, Univ. Tokyo, ${ }^{2}$ AIST)

Yeast cytoplasmic dynein (CD) motor proteins walk processively along a microtubule (MT). What path does CD move along a MT? To address this question, we developed three-dimensional tracking assay which allowed the CD-coated beads to move freely along and around the MT anchored on an etched glass as a suspension bridge, unhindered by glass surface. Observing movement of the CD-coated beads among all surfaces of the suspended MT, we found that the CD-coated beads moved laterally toward both the right and the left, when it moves toward the minus end of the MT. Our analysis showed that $\mathrm{CD}$ does not follow the MT's protofilament $(\mathrm{Pf})$ axis, but that $\mathrm{CD}$ takes a route switching randomly between Pfs with a bias toward the right, inducing the mainly right-handed corkscrew path.

$1 \mathrm{P} 152$

細菌ベん毛モーター固定子複合体のイオン透過メカニズム Ion permeation mechanism through the stator complex in the flagellar motor

Yasutaka Nishihara ${ }^{1}$, Akio Kitao ${ }^{2}\left({ }^{1}\right.$ Univ. of Tokyo, CMSI, ${ }^{2}$ Univ. of Tokyo, $I M C B)$

Bacterial flagellar motors are powered by ions (protons in Escherichia coli and sodium ions in Vibrio alginolyticus). The motor consists of a rotor and stators. The stator acts as a torque generation unit and comprises MotA and MotB protein in E. coli or PomA and PomB protein in $V$. alginolyticus. However the molecular mechanism for torque generation is still unclear. To investigate the structural changes coupled with ion permeation through the stator, we performed molecular dynamics calculations with our model structures. Our results showed that the movements of helices in MotA and MotB were induced by ion permeation. We will also discuss the difference between the helix movements of MotA/MotB and PomA/PomB.

\section{$1 \mathrm{P154}$ LC1 Binds to the Stalk of the Outer Arm Dynein}

Muneyoshi Ichikawa ${ }^{1}$, Kei Saito ${ }^{1}$, Haru-aki Yanagisawa ${ }^{1}$, Toshiki Yagi ${ }^{1,2}$, Ritsu Kamiya ${ }^{1,3}$, Yasuharu Kushida ${ }^{4}$, Kentaro $\mathrm{Nakano}^{4}$, Osamu Numata, Yoko Y. Toyoshima ${ }^{1}\left({ }^{1}\right.$ The Univ. of Tokyo, ${ }^{2}$ Pref. Univ. of Hiroshima, ${ }^{3}$ Gakushuin Univ. ${ }^{4}$ Univ. of Tsukuba)

Outer arm dynein (OAD) complex drives beating of flagella/cilia. OAD complex is composed of three heavy chains $(\alpha, \beta, \gamma \mathrm{HCs})$, intermediate chains (ICs), and light chains (LCs), but the exact subunit architecture has not been elucidated.

$\mathrm{LC} 1$ is a $22-\mathrm{kDa}$ light chain and widely preserved among many species. To directly label the LC1 in ODA complex, we expressed recombinant Histagged LC1 in Tetrahymena and Chlamydomonas. By electron microscopy aided by Ni-NTA-gold labeling, LC1 was found at the $\gamma$-stalk (Chlamydomonas), unlike the previous assumption that $\mathrm{LC} 1$ bound at the $\gamma$-head. Pull-down assay revealed that LC1 preferentially binds to $\gamma$-stalk at 1:1 molar ratio. These results raise the possibility that $\mathrm{LC} 1$ regulates $\mathrm{OAD}$ activity by changing its affinity to microtubules.

\section{$1 \mathrm{P} 155$ 溶媒を陽に考慮した全原子分子動カ学シミュレーションから 得られたダイニンの弾性}

Elastic property of dynein motor domain obtained from allatom molecular dynamic simulations in explicit water

Narutoshi Kamiya ${ }^{1}$, Tadaaki Mashimo ${ }^{2}$, Yu Takano ${ }^{1,3}$, Takahide $\mathrm{Kon}^{4,5}$, Genji Kurisu ${ }^{1}$, Haruki Nakamura ${ }^{1}\left({ }^{1} I P R\right.$, Osaka Univ., ${ }^{2} A I S T,{ }^{3} J S T$, CRESTO, ${ }^{4}$ Hosei Univ., ${ }^{5} J S T$, PRESTO)

Dyneins are large microtubule motor proteins. ADP-bound high-resolution structures have revealed the organization of the dynein motor domain which comprises the AAA+ ring, the linker, stalk/strut and $\mathrm{C}$ sequence. However, a high-resolution ATP-bound dynein conformer remains unclear. We modeled the ATP-bound form, and carried out a 200-ns molecular dynamics simulation for both ADP- and ATP-bound forms using our psygene-G program to investigate the effect of ATP on the structure and dynamics. The stalk of the ATP-bound form was more flexible than that of the ADP-bound form. Two additional 50-ns simulations starting from the ADP-bound form with ATP ligand reproduced this flexibility. The rigidness of both obtained trajectories qualitatively agrees with experimental results.

\section{細菌吕型分泌装置の回転運動およびェフェクター分泌に対す る高粘性高分子の物理化学的影響評価}

Evaluation of physicochemical effect of viscous polymers toward rotation and effector secretion of bacterial type III secretion apparatus

Takashi Ohgita, Naoki Hayashi, Naomasa Gotoh, Kentaro Kogure (Kyoto Pharm. Univ.) The rotor V1-DF is composed of both anti-parallel coiled coil globular-loop parts. Single molecular analysis indicates that an anti-parallel coiled-coil domain of V1-D functions as a rotor in A3B3. Contrary, FliJ protein from flagellar, also composed of an anti-parallel coiled-coil, did not show the unidirectional rotation.

In this study, we report the essential region of $\mathrm{D}$ subunit for unidirectional rotation by a domain swapping approach.
Like drug-injection, bacteria inject effector proteins into host cells via needle-like type III secretion apparatus (T3SA). However, the mechanism of effector transport through T3SA is unclear. T3SA shows structural similarities with flagellum. Effector secretion via T3SA requires protonmotive force (PMF) like flagellar rotation. Based on the facts, we hypothesized that T3SA would secrete effectors by PMF-dependent rotation. Previously, we succeeded in observing PMF-dependent T3SA rotation. In this study, we examined whether the rotation correlates with the secretion. The effector secretion was suppressed, when T3SA rotation was physicochemically inhibited by viscous polymers. Consequently, it was suggested that effector secretion is induced by T3SA rotation. 